\title{
STUDI KEMAMPUAN PEMBEBANAN MAKSIMUM SISTEM INTERKONEKSI SUMBAGSEL
}

\author{
Asdian, Lukmanul Hakim, Endah Komalasari, Herri Gusmedi \\ Jurusan Teknik Elektro Fakultas Teknik \\ Universitas Lampung \\ Jl. Prof. Soemantri Brojonegoro No.1 Bandar Lampung 35145 \\ Purgatory_vader_die@yahoo.com
}

\begin{abstract}
Abstrak
Sistem tenaga listrik merupakan sistem interkoneksi antara pusat pembangkit, transmisi dan beban. Apabila terjadi gangguan pada salah satu sistem karena adanya beban lebih dan ketidakstabilan tegangan, akan berpengaruh ke sistem yang lain, maka perlu ada upaya untuk mencegah terjadinya gangguan tersebut. Salah satunya dengan mengetahui kemampuan pembebanan maksimum setiap beban agar kestabilan sistem dapat tetap terjaga dan dapat meminimalisir terjadinya pemadaman listrik. Penelitian ini bertujuan untuk mengidentifikasi bus-bus beban yang mendekati batas operasi yang diijinkan berdasarkan nilai $\lambda$ dalam sistem interkoneksi Sumatera Bagian Selatan (Sumbagsel). Simulasi dilakukan dengan menggunakan Predictor - Corrector Method Continuation Power Flow untuk mendapatkan nilai $\lambda$ dalam sistem tersebut. Dari hasil simulasi yang dilakukan, diperoleh nilai titik operasi dan titik jatuh dalam setiap beban sistem.
\end{abstract}

Kata kunci : kemampuan pembebanan maksimum, bus-bus beban, titik jatuh

\begin{abstract}
An electric power system interconnection system is among a plant, transmission and load. In the event of disruption in one system due to overload and voltage instability, will affect other systems, it is necessary to attempt to prevent the occurrence of such disorders, one of them by knowing the maximum loadability of each load for voltage stability and minimalize cut off an electric. This study aimed to identify the load buses are approaching the limit of allowable operations based on the value of $\lambda$ in the system interconnection South of Sumatera (Sumbagsel). Simulation is done using Predictor - Corrector Method Continuation Power Flow to obtain the value of $\lambda$ in the system. From the simulation results, the value of the operating point and point load falls within any system.
\end{abstract}

Keywords : maximum loadability, load buses, point load falls

\section{PENDAHULUAN}

Pada saat ini, kebanyakan sistem tenaga listrik sudah merupakan sistem interkoneksi antara satu pusat pembangkit dengan pembangkit lainnya dengan harapan apabila salah satu dari pusat pembangkit atau saluran transmisi mengalami gangguan maka pasokan tenaga listrik tetap dapat berjalan. Di sisi lain, interkoneksi sistem tenaga listrik juga mempunyai beberapa kelemahan. Salah satu kelemahannya adalah apabila terjadi gangguan pada salah satu sistem karena adanya beban lebih dan ketidakstabilan tegangan, akan berpengaruh ke sistem yang lain. Gangguan yang pada awalnya bersifat sementara dan terjadi pada bagian sistem yang mengalami gangguan, jika tidak ada tindakan perbaikan untuk mengatasi gangguan tersebut maka gangguan akan tetap berlangsung dan terjadi pelepasan bertingkat yang pada akhirnya akan mengakibatkan pemadaman total. Oleh karena itu perlu adanya upaya untuk mencegah terjadinya gangguan tersebut, salah satunya dengan tetap menjaga kestabilan daya di setiap bus beban dalam sistem dengan cara mengetahui kemampuan pembebanan maksimum (maximum loadability). Contohnya yaitu dengan mengetahui batas daya maksimum dari bus beban yang terdapat dalam sistem interkoneksi Sumatera Bagian Selatan. 
Dengan mengetahui dan menjaga batas daya maksimum dari setiap bus beban dalam sistem interkoneksi Sumbagsel, maka diharapkan dapat mengantisipasi terjadinya tegangan jatuh dari bus tersebut maupun interkoneksi, sehingga meminimalisir rugi - rugi daya yang terjadi dan kestabilan daya pada sistem dapat tetap terjaga. Dalam operasi sistem tenaga listrik, selain upaya untuk meminimalisir rugi-rugi daya, faktor penting lainnya adalah menjaga keamanan sistem (security system) dalam operasinya. Keamanan sistem meliputi kegiatan yang direncanakan untuk mempertahankan operasi sistem apabila terjadi kegagalan komponen sistem. Sistem tenaga listrik mempunyai variasi beban yang sangat dinamis dimana setiap detik akan berubah-ubah, dengan adanya perubahan ini pasokan daya listrik tetap dan harus disuplai dengan besaran daya yang sesuai. Bila pada saat tertentu terjadi lonjakan atau penurunan beban yang tidak terduga, maka perubahan ini sudah dapat dikategorikan ke dalam gangguan pada sistem tenaga listrik yakni kondisi tidak seimbang antara pasokan listrik dan permintaan energi listrik akibat adanya gangguan baik pada pembangkit ataupun pada sistem transmisi sehingga mengakibatkan kerja dari pembangkit yang lain menjadi lebih berat. Untuk itu diperlukan satu penelaahan kestabilan agar pembangkit yang terganggu tidak terlepas dari sistem.

\section{TINJAUAN PUSTAKA 2.1 Maximum Loadability dan Kurva PV}

Maximum loadability dapat dirumuskan sebagai masalah optimasi nonlinier statis. Tujuan dari masalah ini adalah untuk menentukan kenaikan beban maksimum dalam sistem tenaga (baik total sistem beban, atau beban pada area tertentu dari sistem, atau beban pada bus tertentu atau set bus), saat sistem memadai dan terbatasnya peralatan. Masalah ini dapat dirumuskan secara matematis sebagai berikut:

$$
\begin{aligned}
& \max \quad \lambda \\
& \boldsymbol{g}(\boldsymbol{x}, \lambda)=g x+\lambda \boldsymbol{D} \\
& l \leq h(x) \leq u
\end{aligned}
$$

di mana $\lambda$ merupakan parameter peningkat beban (load increment parameter), $\boldsymbol{g}(\boldsymbol{x}, \lambda)$ merupakan ketidaksetaraan kendala (inequality constraints), $g x$ merupakan persamaan aliran daya, $h(x)$ merupakan ketidaksetaraan fungsi (functional inequalities) pada sistem tenaga, $l$ dan $u$ merupakan batas atas (upper) dan batas bawah (lower) dalam ketidaksetaraan, dan $\boldsymbol{D}$ merupakan vektor untuk meningkatkan beban. ${ }^{[1]}$

Parameter yang digunakan untuk mengkarakterisasi maximum loadability adalah margin $\lambda_{\max }$ loadability, seperti yang ditunjukkan pada gambar 1 dibawah ini. Margin ini memodifikasi hasil dan daya beban seperti dalam persamaan berikut:

$$
\begin{aligned}
& P_{G 1}=P_{G 0}+\lambda P_{S} \\
& P_{L 1}=P_{L 0}+\lambda P_{D}
\end{aligned}
$$

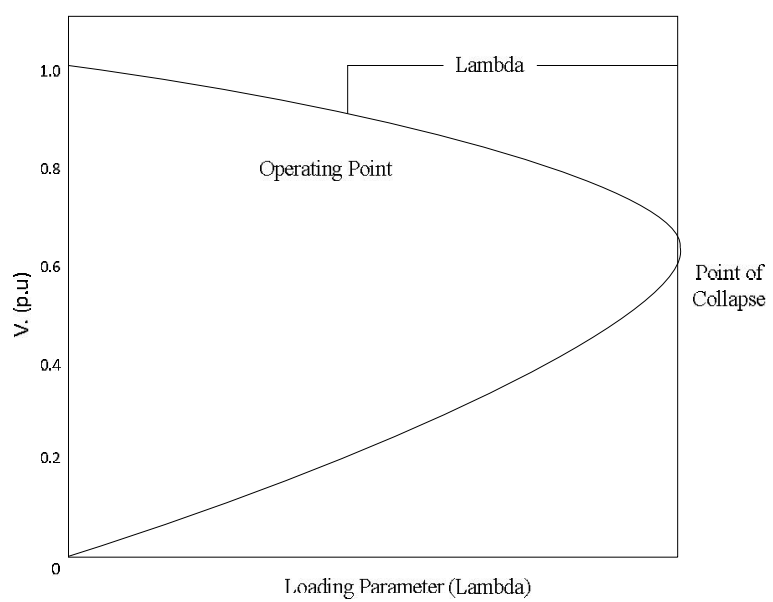

Gambar 1. Maximum loadability parameter $\lambda_{\max }=\lambda+1$

Dimana $P_{G 1}$ merupakan daya maksimum pada pembangkit, $P_{G 0}$ merupakan daya normal pada pembangkit, $P_{S}$ merupakan nilai sumber daya, $P_{L 1}$ merupakan daya maksimum pada beban, $P_{L 0}$ merupakan daya normal pada suatu beban, dan $P_{D}$ merupakan daya yang dibutuhkan.

Persamaan ini biasa digunakan dalam Continuation Power Flow untuk slack bus tunggal. Didalam persamaan, $P_{G 0}$ dan $P_{L 0}$ adalah daya generator dan daya beban yang menentukan kondisi awal (base) dan parameter $\lambda$ (loading factor) menjadi faktor pengali dari $P_{S}$ dan $P_{D}$, yang disebut sebagai arah daya (power directions). Namun, jika arah daya berada diarah vektor didefinisikan oleh $P_{G 0}$ dan $P_{L 0}$, maka persamaan menjadi: ${ }^{2]}$

$$
\begin{aligned}
& P_{G 1}=\lambda_{\max } P_{G 0} \\
& P_{L 1}=\lambda_{\max } P_{L 0}
\end{aligned}
$$




\subsection{Kestabilan Tegangan Sistem Tenaga Listrik}

Kestabilan tegangan sangat berhubungan dengan kemampuan sistem tenaga untuk tetap stabil pada semua bus, tidak hanya dibawah kondisi normal operasi, tetapi juga setelah terjadinya gangguan. Kestabilan tegangan merupakan masalah penting dalam sistem daya modern saat ini. Kebutuhan daya yang sangat besar memungkinkan terjadinya pendekatan batas titik tegangan jatuh dalam sistem.

Dengan meningkatnya kebutuhan daya pada masyarakat, dapat memiliki efek negatif terhadapat kestabilan tegangan. Jika ada sedikit kenaikan pada kebutuhan beban, maka permintaan daya reaktif akan lebih besar dari suplai, dan tegangan akan menurun. Dengan menurunnya nilai tegangan, perbedaan antara suplai daya reaktif dan permintaan menjadi meningkat, dan saat tegangan terus menurun maka akan menjadi nilai yang sangat kecil, kejadian ini biasa disebut sebagai tegangan jatuh. Dalam melakukan analisis kestabilan tegangan, terdapat metode yang digunakan secara umum, yaitu saddle-node bifurcations (SNB).

Suatu sistem tenaga listrik yang baik harus memenuhi beberapa syarat, antara lain sebagai berikut :

a. Reliability adalah kemampuan suatu sistem untuk menyalurkan daya atau energi secara terus menerus.

b. Quality adalah kemampuan sistem tenaga listrik untuk menghasilkan besaran-besaran standar yang ditetapkan untuk tegangan dan frekuensi.

c. Stability adalah kemampuan dari sistem untuk kembali bekerja secara normal setelah mengalami suatu gangguan.

Dalam sistem tenaga listrik yang baik maka ketiga syarat tersebut harus dipenuhi yaitu sistem harus mampu memberi pasokan listrik secara terus menerus dengan standar besaran untuk tegangan dan frekuensi sesuai dengan aturan yang berlaku dan harus segera kembali normal bila sistem terkena gangguan. ${ }^{[3]}$

\subsection{Keamanan Sistem Tenaga Listrik}

Dalam operasi sistem tenaga listrik, selain upaya untuk meminimalisasi rugi-rugi daya, faktor penting lainnya adalah menjaga keamanan sistem (security system) dalam operasinya. Keamanan sistem meliputi kegiatan yang direncanakan untuk mempertahankan operasi sistem apabila terjadi kegagalan komponen sistem. Sebagai contoh, suatu unit pembangkit mungkin harus keluar sistem (off-line) karena kegagalan peralatan pembantu. Dengan mempertahankan sejumlah pembangkit cadangan berputar yang sesuai, unitunit pembangkit yang tersisa pada sistem dapat mengatasi kekurangan daya tanpa turunnya frekuensi yang terlalu rendah atau tanpa perlu melakukan pemutusan beberapa beban (load shedding). Dalam pembangkitan dan pengiriman tenaga listrik, apabila suatu saluran transmisi mengalami kerusakan karena terkena badai sehingga menyebabkan saluran terputus, maka saluran transmisi yang tersisa akan memikul beban yang lebih besar namun masih berada pada batasan yang diijinkan. ${ }^{[4]}$

\section{METODE PENELITIAN}

Dalam paper ini, digunakan metode Continuation Power Flow. Metode ini diimplementasikan kedalam PSAT yang terdiri dari predictor step (tahap prediksi) yang direalisasikan dengan perhitungan tangen vektor dan corrector step (tahap koreksi) yang dapat diperoleh melalui suatu parameter atau persimpangan tegak lurus.

\subsection{Tahap Prediksi (Predictor Step)}

Pada titik kesetimbangan, digunakan persamaan :

$$
\begin{aligned}
\boldsymbol{g}\left(\boldsymbol{y}_{\mathbf{p}}, \lambda_{\boldsymbol{p}}\right) & =\left.0 \Rightarrow \frac{d g}{d \lambda}\right|_{p}=0 \\
& =\left.\left.\nabla_{y} g\right|_{p} \frac{d y}{d \lambda}\right|_{p}+\left.\frac{\partial g}{\partial \lambda}\right|_{p}
\end{aligned}
$$

Dimana $\boldsymbol{g}\left(\boldsymbol{y}_{\mathbf{p}}, \boldsymbol{\lambda}_{\boldsymbol{p}}\right)$ adalah persamaan aliran daya untuk predictor step, $y$ merupakan titik kurva dari tegangan, $p$ adalah keterangan predictor, dan $\lambda$ merupakan titik kurva dari daya. Gambaran dari predictor step terlihat pada gambar 2 dibawah ini: 


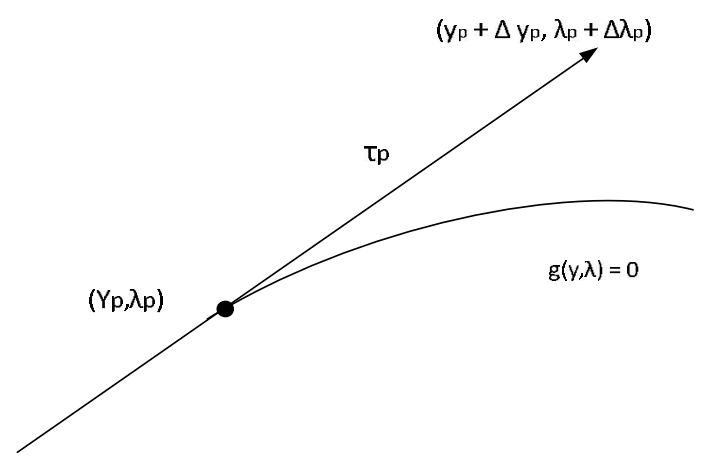

Gambar 2. Continuation Power flow: predictor step.

Dan tangen vektor $\left(\boldsymbol{\tau}_{\boldsymbol{p}}\right)$ dapat dihitung dengan pendekatan berikut:

$$
\boldsymbol{\tau}_{\boldsymbol{p}}=\left.\frac{d y}{d \lambda}\right|_{p} \approx \frac{\Delta y_{p}}{\Delta \lambda_{p}}
$$

Pada titik kesetimbangan, digunakan persamaan :

$$
\begin{aligned}
\boldsymbol{g}\left(\boldsymbol{y}_{\mathbf{p}}, \lambda_{\boldsymbol{p}}\right)=0 & \left.\Rightarrow \frac{d g}{d \lambda}\right|_{p}=0 \\
& =\left.\left.\nabla_{y} g\right|_{p} \frac{d y}{d \lambda}\right|_{p}+\left.\frac{\partial g}{\partial \lambda}\right|_{p}
\end{aligned}
$$

Tangen vektor $\left(\boldsymbol{\tau}_{\boldsymbol{p}}\right)$ dapat dihitung dengan pendekatan berikut:

$$
\boldsymbol{\tau}_{\boldsymbol{p}}=\left.\frac{d y}{d \lambda}\right|_{p} \approx \frac{\Delta y_{p}}{\Delta \lambda_{p}}
$$

Dari persamaan diatas, maka :

$\boldsymbol{\tau}_{\boldsymbol{p}}=-\left.\left.\nabla_{y} g\right|_{p} ^{-1} \frac{\partial g}{\partial \lambda}\right|_{p} \quad \Delta y_{p}=\boldsymbol{\tau}_{\boldsymbol{p}} \Delta \lambda_{p}$

Langkah kontrol $k$ telah dipilih untuk menentukan kenaikan $\Delta y_{p}$ dan $\Delta \lambda_{p}$, dengan normalisasi untuk menghindari besarnya error ketika $\left|\tau_{\mathrm{p}}\right|$ sebesar :

$$
\Delta \lambda_{p} \triangleq \frac{k}{\left|\tau_{p}\right|} \quad \Delta y_{p} \triangleq \frac{k \tau_{p}}{\left|\tau_{p}\right|}
$$

Dimana $\mathrm{k}= \pm 1$, dan ini menentukan kenaikan atau penurunan pada $\lambda$.

\subsection{Tahap Koreksi (Corrector Step)}

Dalam tahap koreksi, $i+1$ (iterasi berikutnya setelah predictor step) persamaan corrector step diselesaikan sebagai berikut:

$$
g(y, \lambda)=0 \quad \rho(y, \lambda)=0
$$

Dimana solusi $g$ harus dalam bifurcation manifold dan $\rho$ persamaan untuk menjamin non-singular pada titik bifurkasi.

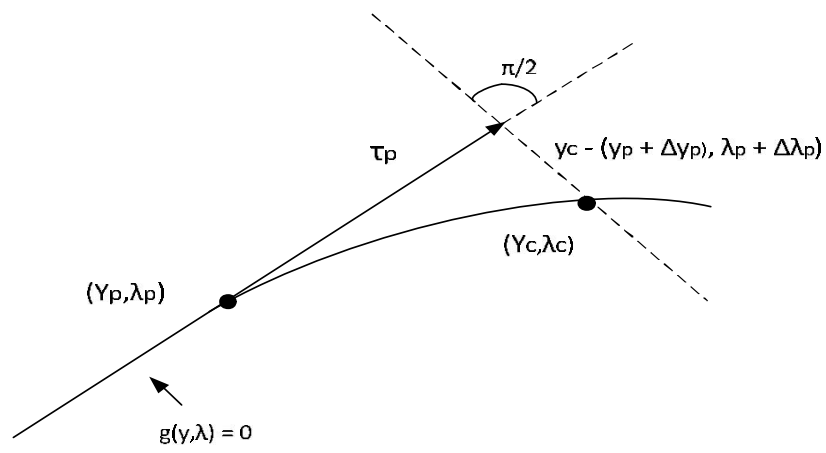

Gambar 3. Continuation Power flow: corrector step diperoleh melalui persimpangan tegak lurus

Didalam kasus persimpangan tegak lurus, pada gambar 3 , persamaan $\rho$ menjadi:

$\boldsymbol{\rho}(\boldsymbol{y}, \lambda)=\left[\frac{\Delta y_{p}}{\Delta \lambda_{p}}\right]^{T}\left[\frac{y_{c}-\left(y_{c}+\Delta y_{p}\right)}{\lambda_{c}-\left(\lambda_{c}+\Delta \lambda_{p}\right)}\right]=0$

Sedangkan untuk parameter lokal, baik parameter $\lambda$ atau variabel $y_{i}$ ditekankan untuk menjadi nilai yang tetap:

Atau

$$
\boldsymbol{\rho}(\boldsymbol{y}, \lambda)=\lambda_{c}-\lambda_{p}-\Delta \lambda_{p}
$$

$$
\boldsymbol{\rho}(\boldsymbol{y}, \boldsymbol{\lambda})=y_{c i}-y_{p i}-\Delta y_{p i}
$$

Pemilihan variabel untuk diperbaiki, tergantung dari nilai bifurcation manifold pada $g$, terlihat pada gambar 4 dibawah ini. ${ }^{[5]}$

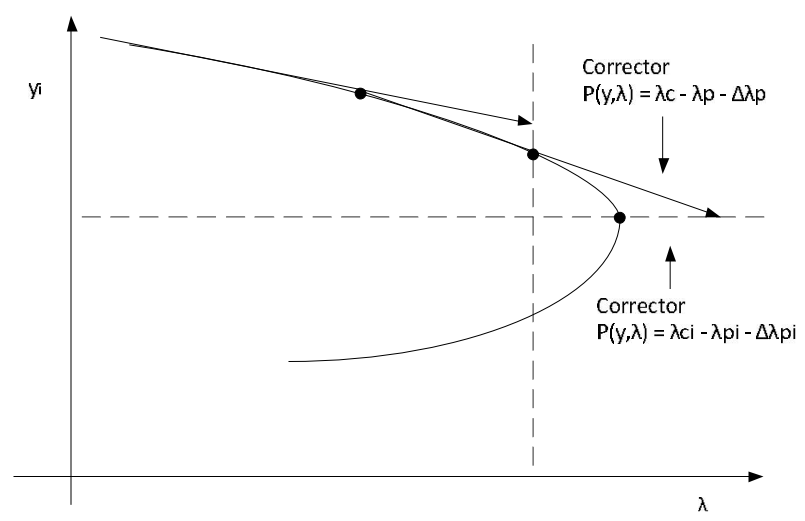

Gambar 4. Continuation Power flow: Tahap Koreksi diperoleh melalui suatu parameter

\subsection{Metode Newton - Rhapson}

Algoritma Newton - Rhapson digunakan untuk menyelesaikan masalah pada aliran daya. 
Tiap iterasi, Jacobian matriks mengikuti persamaan berikut:

$\left[\begin{array}{l}\Delta x^{i} \\ \Delta y^{i}\end{array}\right]=-\left[\begin{array}{cc}F_{x}^{i} & -F_{y}^{i} \\ G_{x}^{i} & G_{y}^{i}\end{array}\right]^{-1} \times\left[\begin{array}{l}f^{i} \\ g^{i}\end{array}\right]$

$\left[\begin{array}{l}x^{i+1} \\ y^{i+1}\end{array}\right]=\left[\begin{array}{l}x^{i} \\ y^{i}\end{array}\right]+\left[\begin{array}{l}\Delta x^{i} \\ \Delta y^{i}\end{array}\right]$

$F_{x}^{i}=\nabla_{\mathrm{x}} f, F_{y}^{i}=\nabla_{\mathrm{y}} f, G_{x}^{i}=\nabla_{\mathrm{x}} g, J_{L F V}=\nabla_{\mathrm{y}} g$.

Dimana $x$ merupakan nilai daya aktif, $i$ merupakan nomor iterasi, $y$ merupakan daya reaktif, $f$ merupakan sudut fasa bus, $g$ adalah tegangan magnitude, $F_{x}^{i}, G_{x}^{i}, F_{y}^{i}, \quad$ dan $G_{y}^{i}$ merupakan komponen Jacobian matriks. Jika variabel $\Delta x$ dan $\Delta y$ lebih kecil dari nilai toleransi $10^{-5}$ atau nilai iterasi melebihi batas yang diberikan $\left(i>i_{\max }\right)$, maka iterasi program akan berhenti. ${ }^{[5]}$

Program disimulasikan menggunakan metode Newton - Rhapson untuk mendapatkan nilai $\lambda$ maksimum. Langkah - langkah simulasi antara lain:

1. Load File Model/Program yang telah dibuat dengan simulink, kemudian Running dengan menggunakan Continuation Power Flow (CPF) untuk mendapatkan nilai $\lambda$ maksimum dan bentuk dari kurva PV.

2. Jika simulink diagram benar, maka Matlab akan memulai iterasi.

3. Setelah iterasi selesai, hasilnya akan mendapatkan nilai $\lambda_{\max }$ pada kurva PV yang dapat dilihat pada Plotting Utilities.

4. Kemudian pilih satu atau lebih $\mathrm{V}$ bus yang diinginkan.

5. Plot untuk memunculkan bentuk kurva tiap bus yang telah dipilih

\section{HASIL DAN PEMBAHASAN}

\subsection{Data Penelitian}

Data penelitian yang digunakan pada paper ini terdapat pada tabel 1 dibawah ini:

\begin{tabular}{|c|l|c|c|c|}
\hline \multirow{2}{*}{ No } & \multirow{2}{*}{ Provinsi } & Pembangkit & \multicolumn{2}{|c|}{ Beban } \\
\cline { 3 - 5 } & $\begin{array}{c}\text { Aktif } \\
\text { (MW) }\end{array}$ & $\begin{array}{c}\text { Aktif } \\
\text { (MW) }\end{array}$ & $\begin{array}{c}\text { Reaktif } \\
\text { (Mvar) }\end{array}$ \\
\hline 1 & $\begin{array}{l}\text { Sumatera } \\
\text { Selatan }\end{array}$ & 1091,800 & 456,468 & 111,8151 \\
\hline 2 & Bengkulu & 241,600 & 144,876 & 49,6579 \\
\hline 3 & Lampung & 780,200 & 603,112 & 223,5960 \\
\hline & Jumlah & 2113,600 & 1204,456 & 385,0690 \\
\hline
\end{tabular}

Tabel 1. Data Pembangkitan dan Beban Sumatera

Bagian selatan (Sumbagsel)

\subsection{Hasil Simulasi dan Analisa}

Penelitian ini hanya akan membahas bagian bus-bus beban yang terdapat pada sistem interkoneksi Sumbagsel. Hasil yang diharapkan berupa kurva PV dan nilai $\lambda$ maksimum yang didapat berdasarkan kesatuan sistem interkoneksi seperti pada single line diagram. Sehingga dapat memberikan informasi lebih detail tentang besarnya daya maksimum yang dapat dioperasikan pada suatu bus tertentu yang ada di wilayah Sumbagsel.

Berikut ini $\mathrm{V}$ bus pada sistem yang memiliki daya beban yang paling tinggi yaitu bus 193 daerah Teluk Betung :

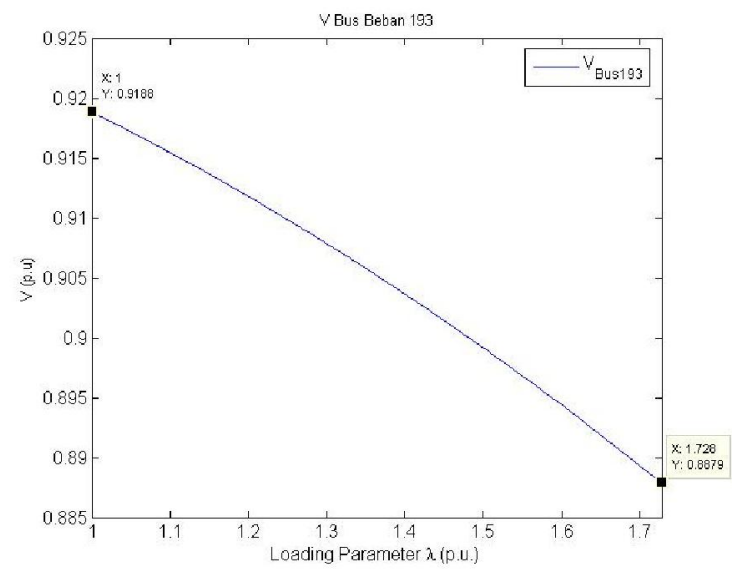

Gambar 5. Kurva PV V Bus Beban 193 daerah Teluk Betung dengan keterangan titik operasi dan titik jatuh

Dari hasil iterasi program yang dijalankan, didapatkan nilai $\lambda$ maksimum adalah sebesar 1,728 p.u dimana kemampuan pembebanan maksimum yang paling tinggi terdapat pada bus 193 yaitu bus 
Teluk Betung (area Lampung) dengan daya maksimum sebesar 82,1477 MW dan daya yang paling rendah terdapat pada bus 177 yaitu bus Ulubelu (area Lampung) dengan daya maksimum sebesar 4,0089 MW.

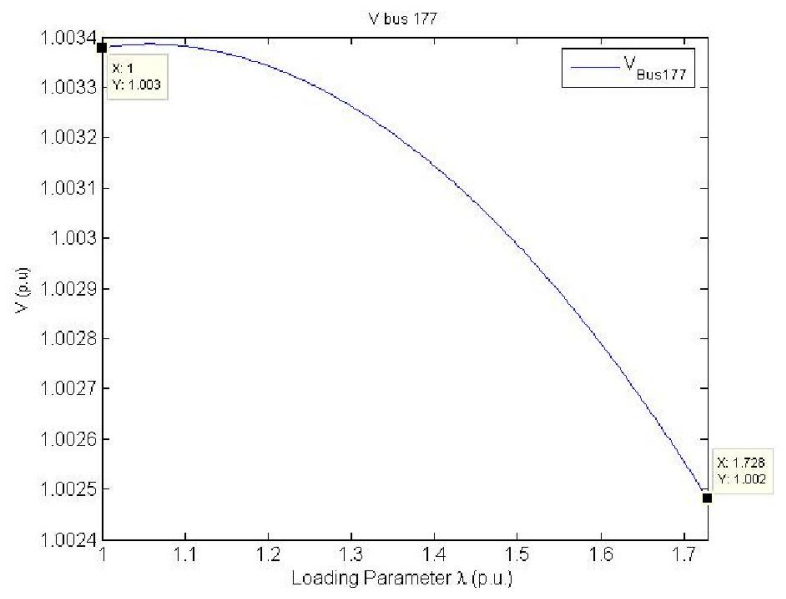

Gambar 6. Kurva PV V Bus Beban 177 daerah Ulubelu dengan keterangan titik operasi dan titik jatuh

Dari gambar 5 dan 6 diatas apabila melebihi nilai $\lambda$ maksimum, maka akan terjadi tegangan jatuh pada sistem. Dari kurva PV bus 193 bahwa nilai $\lambda$ maksimum sebesar 1,728 p.u dengan tinggi tegangan sebesar 0,8879 p.u atau $17,7577 \mathrm{kV}$. Dimana dari titik tersebut dapat diketahui bahwa saat daya maksimum pada bus beban, tegangan menjadi semakin turun. Sehingga penting untuk tetap menjaga kestabilan daya dan tegangan pada bus tersebut untuk mencegah terjadinya tegangan jatuh pada sistem. Dari kurva tersebut juga dapat dilihat titik operasi dengan tegangan 0,9188 p.u atau $18,4942 \mathrm{kV}$. Dimana $\lambda$ yang bernilai 1 p.u atau pada bus ini daya normal bernilai 47,5400 MW. Maka dari itu pada bus 193, besar daya yang dapat di operasikan adalah berkisar antara 1 p.u sampai 1.728 p.u atau 47,5400 MW sampai 82,1477 MW. Berlaku juga dengan bus-bus beban lain dalam sistem dengan besar daya operasi berdasarkan nilai $\lambda$ antara 1 p.u sampai 1,728 p.u.

Dari hasil simulasi, dapat kita lihat pada tabel 2 dibawah ini tentang perbandingan total daya normal dan daya maksimum pada tiap provinsi di Sumbagsel, dimana provinsi Lampung memiliki daya beban yang paling tinggi, sehingga membutuhkan suplai daya yang lebih besar daripada di provinsi Sumatera Selatan.

\begin{tabular}{|c|c|c|}
\hline Provinsi & $\begin{array}{c}\text { Daya Normal } \\
\text { (MW) }\end{array}$ & $\begin{array}{c}\text { Daya Maksimum } \\
\text { (MW) }\end{array}$ \\
\hline $\begin{array}{c}\text { Sumatera } \\
\text { Selatan }\end{array}$ & 455,5580 & 787,1901 \\
\hline Bengkulu & 144,8761 & 250,3412 \\
\hline Lampung & 602,1120 & 1040,4310 \\
\hline Jumlah & 1202,5461 & 2077,9623 \\
\hline
\end{tabular}

Tabel 2. Perbandingan daya normal dan daya maksimum hasil program

Dari gambar 7, dapat terlihat bahwa setelah daya pada tiap beban mencapai nilai maksimum, tegangan dari seluruh beban mengalami penurunan. Dimana tegangan yang paling rendah adalah pada bus 193 yaitu daerah Teluk Betung dengan nilai tegangan sebesar $17,7577 \mathrm{kV}$ dengan nilai tegangan normal sebesar $18,4942 \mathrm{kV}$. Akan tetapi, selisih turun tegangan yang paling tinggi berada pada bus 182 yaitu dari daerah beban New Tarahan, sebesar $0,8165 \mathrm{kV}$, serta daerah lain yang

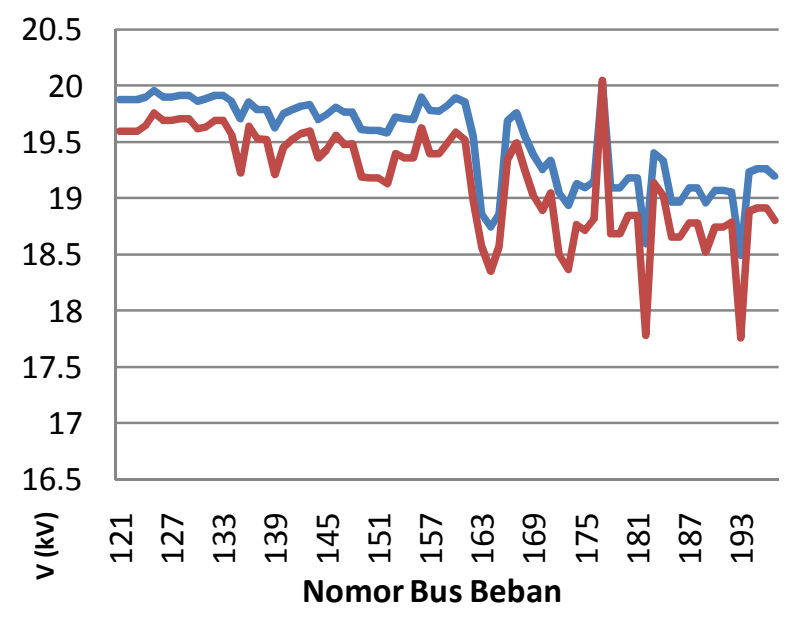

Gambar 7. Perbandingan tegangan normal (biru) dan tegangan setelah kenaikan daya maksimum (merah) tiap bus pada beban sistem Sumbagsel

memiliki selisih turun tegangan yang cukup tinggi seperti pada bus 162, 172 dan 173. Dimana bus 162 merupakan beban didaerah Pekalongan dengan selisih tegangan sebesar $0,5716 \mathrm{kV}$, pada bus 172 yaitu daerah Adijaya, memiliki selisih tegangan sebesar $0,5508 \mathrm{kV}$, dan pada bus 173 
yaitu daerah beban Tegineneng memiliki selisih tegangan sebesar $0,5652 \mathrm{kV}$.

\section{SIMPULAN}

Dari Studi Kemampuan Pembebanan Maksimun Sistem Interkoneksi Sumbagsel, maka dapat disimpulkan bahwa :

1. Dari hasil program sebanyak 200 iterasi, nilai $\lambda$ maksimum yang dihasilkan adalah sebesar 1,728 p.u, dimana bus yang memiliki daya maksimum tertinggi di Sumbagsel terdapat pada bus 193 yaitu bus Teluk Betung, sedangkan bus dengan daya maksimum terendah terdapat pada bus 177 yaitu bus Ulubelu.

2. Nilai daya maksimum yang dapat dioperasikan oleh masing-masing bus pada sistem interkoneksi Sumbagsel dapat diketahui, sehingga dapat dilakukan pencegahan terjadinya tegangan jatuh dengan mengidentifikasi bus-bus yang mendekati titik daya maksimum yang diijinkan.

\section{DAFTAR PUSTAKA}

[1] A.A. Mario and C.A. Carlos. A Contingency Ranking Methode for Voltage Stability in Real Time Operation of Power System. IEEE Bologna Powertech Conference. Italy. 2003.

[2] R.J. Mauricio and Rios A. Mario, Characterization of the Maximum Loadability in Power Systems Due to Contingencies in the Operative Planning Scenari. IEEE Paper 22.

[3] Rosalina. Analisis Kestabilan Tegangan. Universitas Indonesia. Jakarta. 2010

[4] www.unhas.ac.id

[5] F.Milano. Power System Analysis Toolbox. Documentation for PSAT version 2.0.0. 2008 